$\begin{array}{ll} & \text { Etnográfica } \\ \text { etnográfica } & \text { Revista do Centro em Rede de Investigação em }\end{array}$

Antropologia

vol. $14(2) \mid 2010$

Vol. $14(2)$

\title{
Notas breves de uma visita ao futuro do primeiro rei de Portugal com comentário ao catálogo da exposição "D. Afonso - Marca Registada"
}

Brief notes from a visit to the future of the first Portuguese king with comments on the catalogue of the exhibition "D. Afonso - Trade Mark"

\section{Humberto Martins}

\section{(2) OpenEdition}

\section{Journals}

\section{Edição electrónica}

URL: https://journals.openedition.org/etnografica/337

DOI: $10.4000 /$ etnografica.337

ISSN: 2182-2891

\section{Editora}

Centro em Rede de Investigação em Antropologia

\section{Edição impressa}

Data de publição: 1 junho 2010

Paginação: 397-404

ISSN: 0873-6561

\section{Refêrencia eletrónica}

Humberto Martins, «Notas breves de uma visita ao futuro do primeiro rei de Portugal com comentário ao catálogo da exposição "D. Afonso - Marca Registada"», Etnográfica [Online], vol. 14 (2) | 2010, posto online no dia 17 outubro 2011, consultado o 12 fevereiro 2022. URL: http://journals.openedition.org/ etnografica/337 ; DOI: https://doi.org/10.4000/etnografica.337

\section{(c) (1) \&}

Etnográfica is licensed under a Creative Commons Attribution-NonCommercial 4.0 International License. 


\section{Notas breves de uma visita ao futuro do primeiro rei de Portugal com comentário ao catálogo da exposição "D. Afonso - Marca Registada"}

\section{Humberto Martins}

Tendo como ponto de partida uma visita à exposição D. Afonso ${ }^{\circledR}$ (Centro Cultural Vila Flor, Guimarães, 2009), que nos mostrava apropriações diversas, criativamente feitas ao longo do tempo, da imagem do primeiro rei de Portugal, procura-se reflectir sobre o impacte visual da mesma nos seus visitantes. O texto resulta, assim, numa breve etnografia da visita, com referência aos materiais expostos (visíveis e não visíveis), ao mesmo tempo que são projectadas reflexões/questões em torno de como a história e as figuras da história de Portugal são (e podem ser) recordadas, contadas e (co)modificadas.

PALAVRAS-CHAVE: exposição, memória social, história, primeiro rei de Portugal, imaginação.

- PAI, OlHA ALI O HOMEM QUE VIMOS EM CHAVES! - COMO?!, replico, surpreendido e meio perdido. - Ali, naquela carrinha!, responde prontamente Catarina, minha filha de cinco anos. Volto-me e lá estava; uma furgoneta pertencente à marca Calçado Guimarães a fazer uma descarga de material na loja da Praça Gil Vicente em Almada. Sorrio e corrijo: - Sim, mas não foi em Chaves que o vimos; foi em Guimarães, recordas-te? É D. Afonso Henriques, o primeiro rei de Portugal. Esta empresa e as suas carrinhas de transporte têm como imagem de marca a figura do D. Afonso Henriques - com fotografia de destaque nas páginas 146 e 147 do catálogo que acompanhou a exposição D. Afonso ${ }^{\circledR}$ (AAVV 2009) e, em particular, aquela que reproduz a estátua de Soares dos Reis, situada à entrada do Castelo de Guimarães e do Castelo de São Jorge em Lisboa.

Este breve diálogo ocorreu no dia 4 de Setembro de 2009, um pouco antes de deixar a minha filha na escola. Não deixa de ser significativo o facto de 
Catarina ter feito, não voluntariamente, diria, referência à questão crucial que informa quer a produção da exposição (e catálogo) D. Afonso ${ }^{\circledast}$ quer o argumento deste texto: as plurais formas através das quais a imagem de $\mathrm{D}$. Afonso Henriques tem sido apropriada e utilizada ao longo dos tempos e, desde logo, adquirido (outras) vidas próprias para além de um qualquer suposto significado original ou, mesmo, de um local original. A produção da imagem de D. Afonso Henriques, embora associada a Guimarães, por via destes mecanismos de circulação e mercantilização ligados a produtos de consumo mais corrente, como fósforos, papel de carta, facturas e caixas de sapatos (e, como mostra a exposição, estes não são factos novos), torna Afonso Henriques uma coisa menos local (Guimarães até mais que Portugal) e mais global; Afonso Henriques viaja e está um pouco por todo o lado.

Visitáramos a exposição D. Afonso ${ }^{\circledR}$ no dia 20 de Agosto, na tarde de uma quinta-feira de Verão. Eu, a minha companheira Elsa, Catarina e o meu filho André, de dois anos, que queria, "a todo o custo", apropriar-se das pequenas estatuetas de D. Afonso Henriques que ornamentavam um separador junto às escadas de acesso ao primeiro andar deste espaço do Centro Cultural Vila Flor em Guimarães. Durante cerca de hora e meia, só nós os quatro circulámos pela exposição. No exacto momento em que entrámos na sala correspondente ao piso térreo (a exposição dividia-se por este piso, onde se situava a entrada, e por um piso superior com acesso feito por um lanço de escadas), um homem e uma mulher (aparentemente não eram portugueses) com idades acima dos cinquenta anos abandonavam as instalações. De saída perguntei ao funcionário do Centro sobre a afluência de visitantes àquela exposição. Disse-me que nos primeiros dias (a exposição esteve patente entre 24 de Junho e 30 de Agosto de 2009) estiveram muitas pessoas mas que Agosto, normalmente, seria um mês de pouca afluência. Em relação aos visitantes, e segundo o mesmo funcionário, mais teriam sido de Guimarães e muitos teriam ali estado duas ou três vezes. De alguma forma, e porque o acesso automóvel à zona do Castelo e à estátua-símbolo da cidade de Guimarães estava condicionado pelas obras de arranjo urbanístico que decorriam, pensei que, pelo contrário, Agosto fosse período de maior número de visitas ao primeiro rei de Portugal.

Em termos da sua organização no espaço do próprio Centro, a exposição (de acesso gratuito) fazia-nos penetrar num universo iconográfico escolhido e montado pelos seus comissários (Ivo Martins e Vera Velez com aconselhamento científico de Jean-Yves Durand). A porta fechada (apesar de o acesso ser gratuito, a entrada na exposição implicava os visitantes no abrir e fechar de uma porta) levava-nos, de facto, a entrar num universo inescapável de imagens, textos e sons em torno da imagem e da coisa D. Afonso Henriques. Por razão da própria organização espacial, física e material da exposição e desse fechamento, a tons de encarnado (cor que predominava na exposição e no catálogo [com trabalho da designer Vera Velez]), no próprio espaço do Palácio 
Vila Flor, senti(mos) uma espécie de enclausuramento espácio-temporal, que, como direi mais à frente, não significa tanto uma viagem ao passado mas, mais, um convite a olhar de frente (e para a frente) o futuro do primeiro rei de Portugal.

A exposição (e o catálogo) mostram-nos D. Afonso Henriques nas suas mais variadas apropriações e utilizações, mais ou menos contemporâneas, embora salientando a fase de produção maciça durante o Estado Novo, mais ou menos artísticas, mais ou menos populares, através do recurso a colecções públicas e privadas (e, em particular, de Raimundo Fernandes). Entre a exposição clássica de materiais diversos (postais ilustrados, fotografias, estatuária, livros e uma réplica da espada de D. Afonso Henriques), a projecção de imagens e sons (três instalações de vídeo produzidas, originalmente, por Ricardo Freitas e Rodrigo Areias para a exposição, televisores com imagens de arquivo das Festas Gualterianas e com um filme de ficção histórica narrado em língua inglesa sobre as batalhas travadas por D. Afonso Henriques) e um posto de ligação web, que nos remetia para o debate em torno da polémica análise forense às ossadas de D. Afonso Henriques para conhecimento do seu ADN e a não-autorização do acesso e abertura do túmulo pelo Ministério da Cultura, intermediavam-se, em grande formato, fragmentos dos textos que encontramos nas suas versões integrais no catálogo D. Afonso ${ }^{\circledast}$ (AAVV 2009). Os conteúdos e o seu arranjo no espaço mantinham-nos em contacto permanente com o rei, mas também com outras personagens centrais nos processos e mecanismos de utilização da sua imagem, em particular com a obra de Soares dos Reis, autor da famosa estátua que hoje ornamenta o castelo, a cidade e a própria imagem de Guimarães.

Da exposição - e teria sido interessante anexar ao catálogo, através da inclusão de um DVD, os documentos audiovisuais apresentados - importa ainda fazer referência ao facto de os sons das diversas instalações audiovisuais se sobreporem, criando um "ruído" incómodo nalgumas partes do piso superior. Em especial, o som da instalação com imagens da bancada de apoiantes/fãs do Vitória de Guimarães (um vídeo de 2'15" projectado continuadamente) fazia-se ouvir demasiado pelo restante espaço da exposição. Porventura, e porque, de facto, esta apropriação particular (também reconhecível na fotografia de grandes dimensões da bancada sul do estádio do Vitória de Guimarães que acompanha a instalação de vídeo) pelo clube da cidade e seus adeptos tem um peso muito importante nos tempos actuais, aquele som que se impóe pode ser celebratório da mesma. Não será ousado dizer que é no Vitória de Guimarães (clube) e entre os seus adeptos que a imagem de D. Afonso Henriques hoje mais vive, se produz e reproduz.

Este texto situa-se, duplamente, como uma recensão ao catálogo que resulta da exposição D. Afonso ${ }^{\circledast}$ e como uma breve apreciação da referida visita. São, efectivamente, duas perspectivas diferentes, muito embora estas palavras tenham que ver com a própria síntese das duas propostas (a exposição e o 
catálogo). Como em qualquer produção do género, creio que se complementam, embora a obra escrita em texto tenha uma vida autónoma da exposição (muitas vezes, os catálogos propriamente ditos não existem ou, existindo, têm um preço proibitivo).

O intróito escolhido para esta abordagem permitiu-me, pois, estabelecer a coisa, sendo que a coisa não é em si unívoca e unilinear - ou, melhor dito, a coisa são várias coisas. Ou seja, do que falar quando nos propomos compilar e recontar o que foi uma figura histórica (neste caso, o primeiro rei de Portugal e suposto fundador de um país soberano)? A esta pergunta podemos aportar um conjunto de muitas outras perguntas (e questões) que informam os mecanismos de celebração e comemoração dos passados históricos (figuras, eventos e processos), bem como da sua museologização, patrimonialização e apropriação para fins diversos. Como recordam as sociedades? Como mostramos e contamos o passado? Como criamos significado através da elaboração de uma narrativa em torno dos objectos? Qual o trabalho de autoria (critério editorial) subjacente a essa organização? Como situar as audiências face a uma organização intencionada de significados produzidos em torno desses mesmos objectos e figuras do passado? Este debate e questões informam correntemente as preocupações (ou serão obsessões?) patrimonializantes um pouco por todo o mundo. Neste sentido, diria (talvez numa assunção minha muito arriscada), esta exposição expõe os perigos das tentativas essencialistas em torno daquilo que consideramos a patrimonialização dos elementos (materiais e imateriais). Ao mostrar-nos Afonso Henriques como rei de Portugal mas, igualmente, como imagem constantemente criada e recriada, a exposição relembra-nos o argumento clássico de Hobsbawm e Ranger (1995 [1983]) quando nos alertam para a dificuldade de essencializar, ou dizer originais, traços e elementos que julgamos de valor histórico-tradicional. O passado tem sempre um filtro do presente, i.e., o passado é sempre e só acedido através de momentos, pontos de partida que são vividos e/ou propostos a partir de posições sociais (e físicas) do presente.

$\mathrm{Na}$ verdade, a exposição D. Afonso ${ }^{\oplus}$ reacende uma discussão interessante em torno de "como as sociedades recordam" (ou esquecem?), mantendo aqui suspensa a pergunta clássica de Connerton (1993 [1989]), que, aliás, é recuperada recentemente numa sua outra obra intitulada Como Esquece a Modernidade (Connerton 2009; título aqui traduzido livremente) e na qual o autor argumenta em torno de um processo que considera característico das sociedades contemporâneas - o dos esquecimentos culturais desejados e/ou involuntários relativamente aos passados colectivos, às suas histórias. Este debate, para o qual concorre esta exposição, tem nele contida a questão da memória social, pese embora o facto de a exposição ser fruto de um trabalho editorial que não visa propriamente recordar o primeiro rei de Portugal do ponto de vista de uma história oficial do Estado português; pelo contrário, a ruptura com qualquer tentativa de reapropriação oficial do nome Afonso Henriques aparece ao longo 
da exposição (e do próprio catálogo) como o seu grande fio condutor. Não se pretende mostrar como foi (não só quem foi mas, sobretudo, o que foi) efectivamente $\mathrm{D}$. Afonso Henriques. A ideia do que foi D. Afonso Henriques, como coisa (e não só, neste caso, no sentido durkheimiano do termo mas através da sua própria comodificação) e não como pessoa, como homem, é central na exposição. Está subjacente a ideia de marca registada - como produto/objecto histórico? Como produto/objecto contemporâneo? Como produto/objecto de futuro? Como produção estética? Aliás, esta última pergunta parece ser respondida por Ivo Martins no catálogo: “[a]s soluções estéticas contidas em cada um dos documentos e objectos descobertos revelaram-nos um impulso criativo, denunciador de uma vontade de renovar permanentemente a imagem desta personalidade" (2009: 12). Ivo Martins conclui o argumento, remetendo para as ideias de "imaginação colectiva" e de "flexibilidade das representações", o que por si só aparenta uma básica contradição de termos. O lado subjectivo e individual das apropriações (entre caixas de palitos e uma estátua de um escultor como Soares dos Reis muita flexibilidade criativa existe) não deixa, ainda assim, de projectar e sintetizar, numa e naquela imagem, a "visão" de um personagem imponente e grandioso. Tão grandioso como a sua espada, de um peso "humanamente" insuportável. A exposição, aliás, permitia ao visitante pegar e manusear uma réplica (em igual peso e forma) daquela que teria sido a espada de D. Afonso Henriques.

A respeito deste processo de mostragem e desmontagem da imagem e marca D. Afonso ${ }^{\circledast}$, a instalação de vídeo inicial acaba por estabelecer uma ruptura que caracteriza a exposição; várias pessoas em contextos públicos (ruas, jardins, feiras) dão o seu parecer sobre quem foi e onde supostamente terá nascido D. Afonso Henriques. Os quatro vídeos simultâneos (realização e produção de Rodrigo Areias e Ricardo Freitas), apresentados em mosaico numa projecção única continuada, dão-nos versões da história do rei e, seguramente, da história de Portugal. Ouvimos falar de Cristiano Ronaldo, de um guerreiro, e a confusão faz errar o berço do rei entre Guimarães, Viseu e Coimbra. Será, por certo, a isso que Francisca Abreu, vereadora da cultura do município de Guimarães, alude num texto preambular do catálogo da exposição: "Não é objectivo desta exposição comemorar D. Afonso Henriques. Por desnecessário [...] Porque é na memória que se busca e encontra a força e a matéria da criatividade. Porque é da memória passada que se inventam e criam memórias futuras." (2009: 7) A importância da imaginação histórica conceito proposto por Jean-Yves Durand (recuperando o argumento de José Mattoso) - nesta "coisa" de se criar e inventar mitos é, pois, realçada e valorizada ao longo de toda a exposição. Com menor ou maior nível de ambição ou autoridade científica, a imaginação (histórica) presente, passada e futura que vemos retratada não é mais do que o continuado verter de possibilidades (apropriações) feitas pelos portugueses do seu rei fundador. 
A exposição D. Afonso ${ }^{\circledR}$ celebra (comemora), duplamente, o lado futurista do próprio rei - que projectou um país e uma ideia para além do (seu) presente (este será, porventura, o lado menos desejado dos próprios comissários) - e o lado futurista da história de Portugal, reinventada nestas novas possibilidades historiográficas e tecnológicas de a tornar dialógica, discutida e, talvez mais importante neste caso, criativamente estilizada. Naquelas imagens e sons de agora, o rei é democratizado como discurso sobre o que se vê e como texto latente (como ideia, como base cultural de uma cidade e de um país). Esta ideia de futuro, que me parece crucial na exposição, é não só vista e proposta a partir de um hoje, imaginando futuros para o próprio primeiro rei de Portugal, mas, igualmente, a partir do ontem - que é não só um passado presente do próprio Afonso Henriques mas um passado vivido por várias gerações de portugueses, vimaranenses, etc. Os próprios comissários tornam explícita nos seus textos esta necessidade de a exposição funcionar como uma espécie de anticongelante de um "passado" (e de uma história) desejados. Jean-Yves Durand e Ivo Martins referem-no nos textos do catálogo da exposição. Necessariamente, este lado futurista (presente, contudo e como atrás referi, no próprio projecto dinástico de Afonso Henriques) não pode ser (apenas) inscrito no discurso e na prática do rei. " $[\mathrm{O}]$ primeiro rei de Portugal vivia num universo cultural extremamente afastado do nosso, nomeadamente no que diz respeito à relação com o tempo", refere, de modo oportuno, Jean-Yves Durand (2009: 194). Sobretudo, e recorro novamente às palavras de Ivo Martins, existe todo o lado editorial de criação e reinvenção a partir da matéria original (D. Afonso Henriques, primeiro rei de Portugal) que é mostrado e valorizado.

Mas é notável que a própria exposição proponha e tenha conseguido, no meu entendimento, como corpo colectivo, ser em si uma nova representação (produção) sobre o primeiro rei de Portugal. Ela sugere-nos, portanto, conhecer um "novo rei" e, seguramente, não tanto pela exposição (cujo destino desconheço, enquanto conjunto seleccionado, editado e organizado de materiais) mas pelo catálogo e pelas representações produzidas em cada um dos seus visitantes; mais do que a conhecer quem foi $\mathrm{D}$. Afonso Henriques ficamos a indagar o que poderá ser a imagem D. Afonso ${ }^{\circledR}$ no futuro. Parece ser essa a provocação de Jean-Yves Durand quando refere: "nem de longe podemos imaginar se ele teria pensado que a sua imagem ainda pairaria, séculos mais tarde, sobre a nação que contribuiu para formar" (2009: 194). A exposição, neste sentido, refunda a imagem de Afonso Henriques, tal como, anteriormente e ao longo do tempo, o mesmo foi sendo feito por outros e noutras circunstâncias. Na esteira do argumento de Elizabeth Edwards (2002), sobre a objecthood (o carácter, o ser, a história individual) dos objectos e dos materiais expostos, diria que é a coisa D. Afonso que, mostrada através de uma determinada composição (com trabalho editorial envolvido), adquire uma nova vida numa nova versão. Tendo sido vistos e sentidos (tocados inclusive), estes materiais expostos, cujo epicentro 
referencial é a imagem de D. Afonso Henriques, ganharam e ganharão efectivamente uma nova vida e uma nova história (um passado reconfigurado). Mais não seja porque, seguramente, aquela combinação (com escolhas específicas) nunca tinha sido proposta.

O lado iconográfico, de uma produção diversa (espontânea e/ou encomendada) de objectos, imagens, sons, esquissos com base em apropriações, também elas diversas, da figura, de figuras de D. Afonso Henriques (porque ela não é apenas aquela que parece perdurar da estátua de Soares dos Reis) constitui, em suma, o cerne da exposição (e do catálogo). Não é tanto do rei que se fala mas mais de como nós, colectivo de homens e mulheres portugueses, nos temos visto e revisto no "fundador" do "nosso" país. E aí, como tão bem a antropologia nos mostra em muitas outras situações e como podíamos ver no vídeo tetraédrico que abria a exposição, o espelho volta-se para nós e ficamos a conhecer quem somos, o que recordamos, como recordamos e como nos queremos contar. O rei, afinal, é mais uma produção daquilo que não se vê (substratos culturais) do que aquilo que se vê (produtos materializados). Tal como em qualquer marca registada, há um valor do invisível (simbólico ou não) que está sempre subjacente. Neste caso, vemo-lo em caixas de fósforos, em postais ilustrados, em tatuagens gravadas em braços de homens e mulheres apoiantes do Vitória de Guimarães - em traços mais ou menos de ontem e de agora; mas também o sentimos, como referi, em tudo aquilo que a própria exposição projecta e antecipa - em traços de amanhã. A questão que permanece, apropriando-me de uma pergunta que Jean-Yves Durand lança - "o que importa mais: a realidade da estatura [história] do rei, ou o que a imaginação faz dela?" (2009: 212) -, é também a de saber qual o valor comercial (de transacção) da história (de Portugal) e dos elementos patrimoniais que valorizamos como colectivos mais ou menos discerníveis. A celebração da (nossa) história por si só é merecedora de ser etnografada porque são os seus súbditos que fizeram e vão fazendo o primeiro rei de Portugal. E essa imaginação constituirá sempre o futuro do rei e da história de Portugal, tal como constituiu o seu passado e constitui o seu presente. 


\section{BIBLIOGRAFIA}

AAVV, 2009, D. Afonso ${ }^{\circledast}$, catálogo da exposição D. Afonso ${ }^{\circledR}$. Guimarães, Câmara Municipal de Guimarães, A Oficina CIPRL e autores.

ABREU, Francisca, 2009, "Apropriação", em AAVV, D. Afonso ${ }^{\circledast}$, catálogo da exposição D. Afonso ${ }^{\circledast}$. Guimarães, Câmara Municipal de Guimarães, A Oficina CIPRL e autores, 6-7.

COnNerton, Paul, 1993 [1989], Como as Sociedades Recordam. Oeiras, Celta Editora.

—, 2009, How Modernity Forgets. Cambridge, Cambridge University Press.

DURAND, Jean-Yves, 2009, “D. Afonso ${ }^{\circledR}$ : apropriações contemporâneas de um herói nacional”, em AAVV, D. Afonso ${ }^{\circledR}$, catálogo da exposição D. Afonso ${ }^{\circledR}$. Guimarães, Câmara Municipal de Guimarães, A Oficina CIPRL e autores, 194-214.

EDWARDS, Elizabeth, 2002; "Material beings: objecthood and ethnographic photographs", Visual Studies, 17 (1): 67-75.

HOBSBAWM, Eric, e Terence RANGER, 1995 [1983], The Invention of Tradition. Cambridge, Cambridge University Press.

MARTINS, Ivo, 2009, “D. Afonso Henriques: uma viagem iconográfica”, em AAVV, D. Afonso ${ }^{\circledR}$, catálogo da exposição D. Afonso ${ }^{\circledR}$. Guimarães, Câmara Municipal de Guimarães, A Oficina CIPRL e autores, 11-15.

Brief notes from a visit to the future of the first Portuguese king with comments on the catalogue of the exhibition "D. Afonso - Trade Mark" - Humberto Martins - CRIA, UTAD, Portugal • humbmsm@yahoo.com

Following a visit to the exhibition D. Afonso ${ }^{\circledast}$ (Centro Cultural Vila Flor, Guimarães, 2009) which presented many diverse appropriations creatively made of the first Portuguese King's image, a reflection about its visual impact is proposed. Therefore, the text turns out to be a brief ethnography of the visit with reference to the displayed materials (visible and non-visible ones), whereas reflections/questions are suggested on how the Portuguese history and the main characters of Portuguese history are (and may be) remembered, told and (co)modified.

KEYWORDS: exhibition, social memory, history, first king of Portugal, imagination. 